\title{
The Metaphoric Fallacy to a Deductive Inference
}

\section{BRIAN LIGHTBODY}

\section{Michael Berman}

Department of Philosophy

Brock University

St. Catharines, $O N$

Canada L2S $3 \mathrm{Al}$

Emails: blightbody@brocku.ca

Abstract: Our article identifies and describes the metaphoric fallacy to a deductive inference (MFDI) that is an example of incorrect reasoning along the lines of the false analogy fallacy. The MFDI proceeds from informal semantical (metaphorical) claims to a supposedly formally deductive and necessary inference. We charge that such an inference is invalid. We provide three examples of the MFDI to demonstrate the structure of this invalid form of reasoning. Our goal is to contribute to the set of known informal fallacies.

\section{mberman@brocku.ca}

Resumé: Notre article identifie et décrit l'illusion métaphorique à une inférence par déduction (MFDI) qui est un exemple de raisonnement incorrect le long des lignes de l'illusion d'analogie fausse. Le MFDI provient des revendications (métaphoriques) sémantiques informelles à une inférence par supposition officiellement par déduction et nécessaire. Nous chargeons qu'une telle inférence est sans fondement. Nous fournissons trois exemples du MFDI pour démontrer la structure de cette forme sans fondement de raisonnement. Notre but est de contribuer à l'ensemble des illusions informelles connues.

Keywords: analogy, critical thinking, fallacy, metaphor, Nietzsche, Phaedo, reasoning, Sartre.

\section{Introduction}

The metaphoric fallacy to a deductive inference (MFDI) is an example of incorrect reasoning along the lines of the false analogy fallacy. The structure of the MFDI proceeds from analogously relating two metaphors and then claiming that a property (quality or function) from one compared predicate of the analogy is contained by the other predicate. That is, the predication is treated as being transitive across an analogy between metaphors. The essential problem is not simply covered by claims that arguing from analogies is weak, but that the MFDI proceeds from informal semantical (metaphorical) claims to a supposedly formally deductive and necessary inference. We charge that such an inference is invalid.

(C) Brian Lightbody and Michael Berman. Informal Logic, Vol. 30, No. 2, (2010), pp. 185-193. 


\section{Analogies}

Analogies consist of four components, wherein the fourth component involves an inference. The first two components bear a relation to each other that sheds light on the relation between the third and fourth component.

Proposition 1: A is to B

as

Proposition 2: $\mathrm{C}$ is to $\mathrm{D}$

Hence, there needs to be a parallel or equivalent type of relation in propositions 1 and 2 . There can also be the possibility of relations, types, or objects between the first (A) and third (C) components, as well as between the second (B) and fourth (D) components. The type of relations in analogies often prove to be iconic, indexical and symbolic: iconic relations hold when any two components share similar physical characteristics; indexical types are indicative of factual and empirical relations mirrored in the two propositions; and this claim also applies to symbolic relational analysis. ${ }^{1}$

But this points to an assumption about the nature of analogical relations: is there a principle that governs analogies, a principle of analogies? When one claims that two cases are analogous, just what is being asserted? Implicitly understanding one case and recognizing some kind of structural similarity, i.e., relation in another, can lead one to understand the second case. Yet, the nature of analogy is not limited in terms of use to comparisons (or contrasts) of two (or more?) cases. One could in certain instances claim that $x$ is analogous to $y$, e.g., Merleau-Ponty claims in "Indirect Language and the Voice of Silence" that painting is analogous to writing ${ }^{2}$ - in this case both involve creative expression, which would be indicative of an iconic relation. Hence, Merleau-Ponty's analogical argument, one that aims at inferring a fourth component, would look like this:

Proposition 1: Painting is to a painter

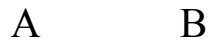

as

Proposition 2: Writing is to a writer

C D

$\mathrm{A}$ and $\mathrm{C}$ are iconic as are $\mathrm{B}$ and $\mathrm{D}$, yet we must also add that $\mathrm{B}$ and $\mathrm{D}$ bear indexical relations toward $\mathrm{A}$ and $\mathrm{C}$ respectively, which

\footnotetext{
${ }^{1}$ Peirce, accessed online January 3, 2010: http://www.marxists.org/reference/subject/philosophy/works/us/peirce2.htm.

${ }^{2}$ Merleau-Ponty, pp. 44-45.
} 
is the relation that grants or validates the inference to D. The mechanics of cognitive application of the analogical principle rely on these various relations, for without the paralleling of the relations in propositions 1 and 2, there would be no way to make valid, understandable inferences to the fourth component $\mathrm{D}$.

Analogical arguments are supposed to demonstrate that because two things or situations are similar in some way, then what would obviously hold true for one would therefore hold true for the other. ${ }^{3}$ Fallacious analogical arguments are those wherein the similarity between the two components being compared is questionable or irrelevant. The so-called similarity is neither sufficient nor relevant to draw the conclusion the arguer wishes to make. The argument is referred to as a bad, questionable, or, false analogy. ${ }^{4}$ For example:

1) Human communities are analogous to beehives.

2) All beehives need a queen.

3) Therefore all human communities need a queen.

Notice that in this case the analogy is questionable because the conclusion that the arguer wishes to draw is not relevant to the similarity (if there is one) between beehives and human communities. However, if the analogical argument is altered to read:

1) Human communities are analogous to beehives.

2) All bees in a beehive need to work together in order for the hive to function.

3) Therefore all humans in a community need to cooperate with one another in order for the community to function.

Then it is clear that the argument is much stronger. Communities exist because members of communities perform vital tasks for the very survival of the community. Of course we could question whether it holds true that all humans need to have a function in a community, but this is beside the point. The second argument is much stronger analogically speaking than the first because it dem-

\footnotetext{
${ }^{3}$ Patrick Hurley defines an analogical argument as follows: “An argument from analogy is an argument that depends on the existence of an analogy, or similarity, between two things or states of affairs. Because of the existence of this analogy, a certain condition that affects the better known thing or situation is concluded to affect the similar, lesser known thing or situation" (p. 34).

${ }^{4}$ Hausman, Kahane and Tidman claim: "The fallacy of questionable analogy, or faulty comparison, consists in comparing apples with oranges, that is, in reasoning by analogy when there is not a sufficient or relevant similarity between the items being compared" (p. 366).
} 
onstrates that human communities and beehives share a similar attribute: both are organizations, and individuals within each organization must perform specific functions in order to ensure its survival.

\section{Metaphors}

The use of metaphorical propositions deeply problematizes analogical reasoning. Metaphors, novel ones and dead versions, ascribe new and unique properties to one component of these propositions. The relations employed in these propositions are simple predications. Hence when metaphorical propositions are used in an analogy the kind of relation that such arguments can rely on for inferences to a fourth component is quite circumspect. The relations between the components in each proposition can only be predications of a quality or property, i.e., is or is like-mere connection. So then to determine an inference in an analogy with one or more metaphorical propositions, the metaphors that guide the understanding can only be those between components A and C. If, however, component $\mathrm{B}$ is used to generate the inference to $\mathrm{D}$ then it is more than likely to either mix the metaphor or simply duplicate the predication of $\mathrm{B}$ into proposition 2 (essentially assuming what one wishes to prove or merely claiming as a conclusion what one accepted as a premise).

Proposition 1: Pavorotti is like a singing angel

A

B

as

Proposition 2: Michaelangelo is like a painting angel

C D

\section{The metaphorical fallacy to a deductive inference (MFDI)}

Given the discussion above, it is clear that the MFDI is a subset of the false analogy fallacy. It does not need to posit or assume a particular type of analogy or metaphor. It is acceptable to assume that a metaphor can indicate a transferring of information from one particular (predicate) to another particular (subject), that is, the ascription of some property, quality or function to the target occurs. Making an inference or argument from a subject to the target via an analogy is also presupposed. The relation between the source and the target themselves may, though not necessarily, include a similarity.

The MFDI also assumes that a metaphor is the description of one thing as something else. It need not be taken as a factual claim 
insofar as such is subject to truth conditions. Rather, a metaphor can provide an expression of insight which elicits or prompts thought in new directions. "Metaphors do not always have a point." Additionally, a metaphor can serve as a means to articulate the ambiguities and nuances inherent in experience. It is formed through a series of transformations, movements above and across. Conceptually speaking, the metaphor carries over and crosspolinates (a metaphor itself) the subject term's meanings with that of the predicated term's meanings. In this manner, connotative and denotive meaning can contribute to the connotative meaning of the subject term. We then ought to heed Mikel Dufrenne's warning: "we must not be the dupes of metaphor, however legitimate it may be." "

According to Hausman, Tidman and Kahane, "fallacious reasoning is just reasoning that is not cogent, which means reasoning that either (1) does not provide sufficiently good grounds for its conclusion; (2) employs unwarranted premises; or (3) ignores or overlooks relevant information." "So the fallacy is committed because a premise that comes from a faulty analogy cannot provide a deductive inference (basically there is no syllogism at all), and secondly, even with the most charitable reading of a metaphorical premise that translates it as a proposition, the argument would still be invalid. We show this with the following.

Consider the example of the heart:

1. The heart is like a mechanical pump.

2. The heart is like a red, red rose.

3. Hence from (1) and (2), a mechanical pump is like a red, red rose.

4. A mechanical pump can be fixed.

5. Therefore, (3) since a red, red rose is (like) a mechanical pump, a red, red rose can be fixed.

Formally, the argument can be stated in the following fashion:

Domain: unrestricted

$H x=$ " $x$ is a heart"; $P x=$ " $x$ is a mechanical pump"; $R \mathrm{x}=$ " $x$ is a symbol of love"; and $F x=$ " $x$ is a fixable entity",

\footnotetext{
${ }^{5}$ Dufrenne, p. 180.

${ }^{6}$ Ibid.

${ }^{7}$ Hausman, Kahane and Tidman, p. 357

${ }^{8}$ This is a play on Robert Burns' poem A Red, Red Rose (1794); accessed January 3, 2010: http://wonderingminstrels.blogspot.com/1999/05/red-red-roserobert-burns.html.
} 
a.

1. $H x$ is analogous to $P x$

2. $H x$ is analogous to $R x$.

3. $P x$ is analogous to $R x$. (Inferred from 1 and 2)

4. $(x)(P x \rightarrow F x)$.

5. Therefore, $(x)(R x \rightarrow F x)$. (MFDI)

As is clear from the example (a) this is not a deductively valid argument. The argument is invalid as premise 3 cannot be adequately symbolized since it is uncertain what property a pump shares with a red, red rose. Therefore the third statement does not have a truthvalue. Furthermore, even if we ignore this troublesome statement, the argument is still invalid as it is possible to substitute the following interpretations for the variables in order to generate a counterexample.

Domain: unrestricted

$P x=$ "x is a human," $F x=$ "x is a mammal", $R x=$ "is a biped."

b.

1. $(x)(P x \rightarrow F x)$

2. Therefore: $(x)(R x \rightarrow F x)$

The argument is obviously invalid as not all bipedal creatures are mammals.

We can also generate a short truth table to prove invalidity as well. If we make $P x$ false and $F x$ false for premise 1, this makes the material conditional true. If we make $R x$ true and maintain the same value for $F x$, namely, that it is false, then this conditional is false. Thus, we have shown that the argument is invalid because it is possible for the premises to be true and yet for the conclusion to be false.

Indeed, even if we go beyond all bounds of interpretative charity and symbolize premise 3 in (a) as $(x)(P x \rightarrow R x)$ we still cannot conclude $(x)(R x \rightarrow F x)$. The conclusion still does not follow because we cannot validly conclude from this line, that every symbol of love is a fixable entity. The argument is again invalid if we substitute the same interpretations we used in (b) and our domain of discourse remains unrestricted.

1. $(x)(P x \rightarrow R x)$

2. $(x)(P x \rightarrow F x)$

3. Therefore: $(x)(R x \rightarrow F x)$

Again, if we presume that all humans are bipedal, this does not entail that all bipedal creatures are mammals. 
Again looking at this same argument from the point of view of the short truth table test for invalidity, we can see that since a material conditional is only false if and only if the antecedent is true and the consequent false, then $R x$ must be true and $F x$ false. If we make $F x$ false in line 2 then $P x$ would have to be false in order to make the conditional true. If $P x$ is false and $R x$ is true then the conditional is still true as a whole. Thus, once more, we have shown the argument to be invalid.

The MFDI is thereby committed when the following two conditions are fulfilled: (i) a faulty comparison is made between two things (false analogy); and (ii) this faulty comparison is then used as a premise in a sub-argument that is supposed to prove some conclusion which is believed to follow deductively. However, this subargument is, as we have shown, invalid. Thus there is a metaphorical fallacy that (invalidly) leads to a deductive inference (MFDI).

In the following, (c) and (d), we present two examples of the MFDI as found in the philosophical literature. The first is taken from Plato's corpus, while the second is of a more recent vintage.

c. “Cebes's Objection" in Plato's Phaedo (86e-88d):

1. The soul is (like) a weaver's coat.

2. The soul is (like) the principle of life.

3. Hence, the principle of life is (like) a weaver's coat.

4. A weaver's coat can wear out.

5. Therefore, since the principle of life is (like) a weaver's coat, the principle of life can wear out, i.e., can be non-life.

In the Phaedo, wherein Plato has Socrates respond to Cebes's objection to the soul's supposed immortality with a discussion about the nature of opposites, we can discern an example of the MFDI. One could object to this reconstruction by claiming that statement c. 2 is an a priori analytic proposition. For the sake of this argument, we treat the proposition as a metaphor. As is evident in c.5, the inference leads to a contradiction: the wearing out of the weaver's cloak is a metaphor for mortality. The argument amounts to claiming that the principle of life can end in death. Socrates addresses the absurdity of this claim by explaining the exclusionary relation between life and death, and then applying the principle of non-contradiction.

We now turn to a more contemporary example of the MFDI: 
d. "Sartre and Nietzsche" by Christine Daigle in Sartre Studies International, 10.2 (December 2004), 195-211.

1. All resolutions to nihilism are like becoming the Nietzschean overman.

2. All resolutions to nihilism are like becoming the Sartrean authentic man.

3. Hence, becoming the Nietzschean overman is like becoming the Sartrean authentic man.

4. Becoming the Nietzschean overman includes becoming a child and loving fate.

5. Therefore, since becoming the Nietzschean overman is like becoming the Sartrean authentic man, then becoming the Sartrean authentic man includes becoming a child and loving fate.

\begin{tabular}{|c|c|}
\hline $\begin{array}{l}\text { Qualities of the Nietzschean } \\
\text { Overman }\end{array}$ & $\begin{array}{l}\text { Qualities of the Sartrean Au- } \\
\text { thentic Man }\end{array}$ \\
\hline $\begin{array}{l}\text { 1. self-propelling wheel } \\
\text { 2. self-overcoming } \\
\text { 3. child } \\
\text { 4. sacred Yes and Amen } \\
\text { 5. love offate (amour fati) } \\
\text { 6. artist/aesthetic phenome- } \\
\text { non } \\
\text { 7. saint/lover } \\
\text { 8. philosopher/knower } \\
\text { 9. dynamic }\end{array}$ & $\begin{array}{ll}\text { 1. } & \text { not in bad faith } \\
\text { 2. } & \text { self- } \\
\text { accomplished/project } \\
\text { 3. } x \\
\text { 4. } \text { self-justification by } \\
\text { for-itself } \\
\text { 5. freedom } \\
\text { 6. artist/creator } \\
\text { 7. } x \\
\text { 8. gives meaning to Be- } \\
\text { ing } \\
\text { 9. becoming }\end{array}$ \\
\hline
\end{tabular}

Qualities not identified by Daigle are italicized.

Daigle concludes the article in this fashion: since Nietzsche and Sartre share the common concern of resolving nihilism and their respective means of resolution are analogously comparable, then one can state that they are "existentialist" brothers in arms (a metaphor itself). However, if the analogy between becoming the Nietzschean overman and becoming the Sartrean authentic man is strong, then one need not read Sartre who would be saying nothing beyond the metaphors that Nietzsche employs. In contradistinction, if the analogy is weak (as the author admits with the adverbial use of the term "tentative" for the conclusion), then the author's argument overstates the case. Since the inference can lead to numerous indeterminate conclusions, then we may even conclude that the Sartrean authentic man is like a saint or that he is like a self- 
propelling wheel, etc. We contend that the faulty reasoning employed in the argument described above in (d) necessitates such a conclusion. This faulty reasoning serves as the paradigmatic case for the MFDI.

\section{Conclusion}

The intent of this short article is to provide another entry to the list ${ }^{9}$ of informal fallacies, and to explicitly identify examples of faulty reasoning that have been employed in the philosophical tradition. Our assumption is that the MFDI is also employed in the wider field of literature in general, but providing evidence for this claim is beyond the purview of this present exercise.

\section{Acknowledgements}

The authors would like to thank our colleagues Professors Christine Daigle, Rohit Dalvi and Rajiv Kaushik for their valuable inspiration and advice.

\section{References}

Burns, Robert. (1794). My Heart is like a Red, Red Rose.

Daigle, Christine. (2004). "Sartre and Nietzsche." Sartre Studies International, 10.2, December, 195-211.

Dufrenne, Mikel. (1966). The Notion of the A priori. U.S.A. Northwestern University Press.

Hausman, Alan, Howard Kahane, and Paul Tidman. (2007). Logic and Philosophy: A Modern Introduction Tenth Edition. U.S.A. Thomson-Wadsworth.

Hurley, Patrick. (2006). A Concise Introduction to Logic Ninth Edition. Belmont, California. Wadsworth.

Merleau-Ponty, Maurice. (1964). Signs. Illinois. Northwestern University Press.

Peirce, Charles Sanders. (1955). Philosophical Writings of Peirce. Editor, Justus Buchler. United Kingdom. Dover.

Plato. (1999). Great Dialogues of Plato. Trans. W.H.D. Rouse. New York. Signet Classics.

\footnotetext{
${ }^{9}$ There are 85 entries listed on the following website (accessed March 9, 2009): $\mathrm{http}: / /$ theautonomist.com/aaphp/permanent/fallacies.php.
} 